\title{
Oxygen Evolution Reaction on Nitrogen-Doped Defective Carbon Nanotubes and Graphene
}

\author{
Garold Murdachaew*(ㄱ) and Kari Laasonen ${ }^{\circledR}$ \\ Department of Chemistry and Materials Science, Aalto University, P.O. Box 16100, FI-00076 Aalto, Finland \\ Supporting Information
}

ABSTRACT: The realization of a hydrogen economy would be facilitated by the discovery of a water-splitting electrocatalyst that is efficient, stable under operating conditions, and composed of earth-abundant elements. Density functional theory simulations within a simple thermodynamic model of the more difficult half-reaction, the anodic oxygen evolution reaction (OER), with a single-walled carbon nanotube as a model catalyst, show that the presence of $0.3-1 \%$ nitrogen reduces the required OER overpotential significantly compared to the pristine nanotube. We performed an extensive exploration of systems and active sites with various nitrogen functionalities (graphitic, pyridinic, or pyrrolic) obtained by introducing nitrogen and simple lattice defects (atomic substitutions, vacancies, or Stone-Wales rotations). A number of nitrogen functionalities (graphitic, oxidized pyridinic, and Stone-Wales pyrrolic nitrogen systems) yielded similar low

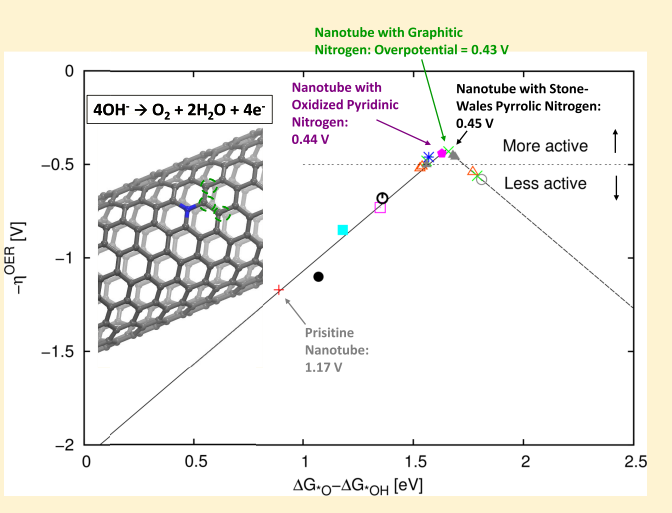
overpotentials near the top of the OER volcano predicted by the scaling relation, which was seen to be closely observed by these systems. The OER mechanism considered was the four-step single-site water nucleophilic attack mechanism. In the active systems, the second or third step, the formation of attached oxo or peroxo moieties, was the potential-determining step of the reaction. The nanotube radius and chirality effects were examined by considering OER in the limit of large radius by studying the analogous graphene-based model systems. They exhibited trends similar to those of the nanotube-based systems but often with reduced reactivity due to weaker attachment of the OER intermediate moieties.

\section{INTRODUCTION}

The often intermittent nature of renewable energy sources requires a scalable energy storage medium. Hydrogen $\left(\mathrm{H}_{2}\right)$ generated from electrolytic water splitting can serve in this role. Thus, efficient electrolyzers, combined with fuel cells and also metal-air batteries, hold the promise of a clean and sustainable global energy infrastructure. ${ }^{1-5}$ However, while the hydrogen evolution reaction (HER; in acidic medium: $\left.2 \mathrm{H}^{+}(\mathrm{aq})+2 \mathrm{e}^{-}(\mathrm{aq}) \rightarrow \mathrm{H}_{2}(\mathrm{~g}) ; \Delta G^{\exp } \approx 0 \mathrm{eV}\right)$ at the electrolyzer cathode is a two-step, two-electron process and relatively facile, the oxygen evolution reaction (OER; in alkaline medium: $4 \mathrm{OH}^{-}(\mathrm{aq}) \rightarrow \mathrm{O}_{2}(\mathrm{~g})+2 \mathrm{H}_{2} \mathrm{O}(\mathrm{aq})+4 \mathrm{e}^{-}(\mathrm{aq})$; $\left.\Delta G^{\exp }=4.92 \mathrm{eV}\right)$ at the anode is sluggish due to the required four-electron transfer. With the ideal catalyst, the kinetic barriers would be vanishingly small, and all four reaction steps would be equal, requiring the application of an external potential of $(4.92 \mathrm{eV}) / 4 e=1.23 \mathrm{~V}$. However, in practice, even the best catalysts require a substantial overpotential $\eta^{\mathrm{OER}}$, resulting in energy loss. (A similar situation holds for the reverse reaction, the oxygen reduction reaction, ORR, occurring at the cathode of a fuel cell.) A practical measure of catalyst efficiency is a sufficient rate of reaction represented by a current density $j$ (e.g., $j=10 \mathrm{~mA} \mathrm{~cm} \mathrm{~cm}^{-2}$, usually in $0.1 \mathrm{M}$ $\mathrm{NaOH}$ or $\mathrm{KOH}$ ), being generated at a not overly excessive overpotential $\left(\eta^{\mathrm{OER}, 10}\right)$ and a not too large Tafel slope that quantifies the required overpotential increase per decade increase in current density. Additional requirements for a broadly useful electrocatalyst include that it contains only earth-abundant materials (e.g., nonprecious metals), exhibits durability under operating conditions, and is simple to manufacture. Thus, intense research continues to develop electrocatalysts capable of fulfilling these requirements ${ }^{4}$ (see Table S1 in the Supporting Information, SI).

For widespread adoption of a hydrogen economy, use of precious metals (e.g., $\mathrm{Ru}, \mathrm{Ir}, \mathrm{Pt},{ }^{6}$ and their oxides) as catalyst materials must be eliminated or sharply reduced through, for example, nanoscaling. ${ }^{6,7}$ Alternatively, nonprecious metals (the transition metals, TMs, e.g., $\mathrm{Mn}, \mathrm{Fe}, \mathrm{Co}, \mathrm{Ni}$; their oxides; ${ }^{8-13}$ and organometallic ${ }^{14}$ compounds) may be used as catalysts. The often poor conductivity of a TM oxide material can be remedied by use of a thin layer of the oxide or an oxide nanocluster decorated on a conducting support. The high conductivity of the nanocarbon materials, carbon nanotubes (CNTs) and graphene (GRA), makes them ideal supports. $^{15-19}$

Received: August 31, 2018

Revised: October 19, 2018

Published: October 24, 2018 
Alternatively, electrocatalysts may be composed of fully metal-free $\mathrm{sp}^{2}$ nanocarbon systems ${ }^{20-24}$ such as CNTs, GRA, graphitic carbon nitride $\left(\mathrm{g}-\mathrm{C}_{3} \mathrm{~N}_{4}\right)$, or their mixtures. Owing to the relatively inert nature of pristine CNTs and GRA, doping (with, e.g., B, N, O, P, or S) or codoping has been observed to improve catalyst performance. ${ }^{25-36}$

As an alternative to doping, the GRA or the sidewall of the CNT may be chemically functionalized with organic or organometallic chemical groups. The effect of the support material and also of the geometry (critical for material flows) has also been examined. The results in terms of low overpotentials and low Tafel slopes are comparable to and occasionally better than even the best precious metal and transition metal oxide catalysts. ${ }^{15-19,26,37}$

Since operando studies of OER catalyst performance are still scarce, ${ }^{38-41}$ density functional theory (DFT) has been employed to elucidate on an atomistic level the OER mechanism, the potential-determining step (PDS), the effects of material composition/doping, and active sites. Note that the DFT thermodynamic approach often neglects solvent contributions and kinetic barriers. Thus, only qualitative trends should be inferred in comparing the DFT and experimental results for a given system. This caveat applies also to the work presented here. Nevertheless, Nørskov, Rossmeisl, and their collaborators have shown that the DFT-based thermodynamic approach yields valuable insights into screening the OER performance trends of metal and metal oxide catalysts. ${ }^{4,42-45}$ DFT studies have also been performed on pristine and doped nanocarbon materials. It was shown that $\mathrm{N}$, the most common dopant atom, withdraws electronic charge from directly adjacent and nearby $\mathrm{C}$ atoms due to its larger electronegativity, thereby transforming them into active sites for ORR, ${ }^{25,46-48}$ $\mathrm{HER}^{49-52}$ and OER. ${ }^{53}$

Recently, Davodi et al. ${ }^{36}$ in an experimental study obtained excellent performance for full water splitting (OER and HER) with a nitrogen-doped CNT-based catalyst fabricated through an efficient and reproducible process. The current work is an attempt to understand those results from an atomistic-level perspective. To describe the thermodynamics of OER, we have used the reaction mechanism and DFT-based model that has been employed to study OER on partially oxidized metals, ${ }^{43}$ metal oxides, ${ }^{42,44}$ and nitrogen-doped graphene. ${ }^{53}$ As in those works, the OER mechanism considered is the four-step singlesite water nucleophilic attack (WNA) mechanism, rather than the radical oxo coupling (ROC) mechanism involving two nearby or adjacent sites ${ }^{54}$ since our preliminary calculations showed that the ROC mechanism on single-walled carbon nanotubes (SWNTs) has much higher kinetic barriers and is thus unlikely. However, the ROC mechanism is believed to be important in water oxidation in biological systems ${ }^{45,55}$ and in certain TM oxide systems. ${ }^{12}$

We performed an extensive exploration on the effect on OER of various defects (vacancies, Stone-Wales rotations, Ndoping, and codoping with $\mathrm{O}$ ) in both single-walled carbon nanotube (SWNT)- and in the corresponding GRA-based systems. SWNT-based systems rather than the multiwalled carbon nanotube (MWNT)-based systems of ref 36 were considered due to the currently intractable computational demands to perform an extensive study of MWNTs. We considered only implicit solvent effects via use of the experimental value of the free energy of $\mathrm{O}_{2}$ formation by electrolysis in an aqueous medium. This approach has been shown to give qualitatively correct results for nonmetallic catalysts. $^{42,44}$

The remainder of this article is organized as follows. An overview of the systems modeled and the computational methods used is given in Section 2. In Section 3, the main results are presented and discussed. Some supporting materials for Sections 2 and 3 are presented in the SI. An outlook and a conclusion are presented in Sections 4 and 5, respectively.

\section{SYSTEMS AND METHODS}

To describe the thermodynamics of OER, we have used the reaction pathway and model that Man et al. ${ }^{42}$ have employed for the process on metal oxide systems. The assumed OER pathway involves four sequential additions of $\mathrm{OH}^{-}$at a site marked “*”

$$
\begin{aligned}
& *+4 \mathrm{OH}^{-} \rightarrow * \mathrm{OH}+3 \mathrm{OH}^{-}+\mathrm{e}^{-}\left(\Delta G_{1}\right) \\
& * \mathrm{OH}+3 \mathrm{OH}^{-}+\mathrm{e}^{-} \\
& \rightarrow * \mathrm{O}+2 \mathrm{OH}^{-}+\mathrm{H}_{2} \mathrm{O}+2 \mathrm{e}^{-} \quad\left(\Delta G_{2}\right) \\
& * \mathrm{O}+2 \mathrm{OH}^{-}+\mathrm{H}_{2} \mathrm{O}+2 \mathrm{e}^{-} \\
& \rightarrow * \mathrm{OOH}+\mathrm{OH}^{-}+\mathrm{H}_{2} \mathrm{O}+3 \mathrm{e}^{-} \quad\left(\Delta G_{3}\right) \\
& * \mathrm{OOH}+\mathrm{OH}^{-}+\mathrm{H}_{2} \mathrm{O}+3 \mathrm{e}^{-} \\
& \rightarrow \mathrm{O}_{2}+2 \mathrm{H}_{2} \mathrm{O}+4 \mathrm{e}^{-}\left(\Delta G_{4}\right)
\end{aligned}
$$

The needed free energies can be obtained from the attachment free energies of the intermediates

$$
\begin{aligned}
& *+\mathrm{OH} \rightarrow * \mathrm{OH} \quad\left(\Delta G_{* \mathrm{OH}}\right) \\
& *+\mathrm{O} \rightarrow * \mathrm{O} \quad\left(\Delta G_{* \mathrm{O}}\right) \\
& * \mathrm{OOH} \rightarrow * \mathrm{OOH} \quad\left(\Delta G_{* \mathrm{OOH}}\right)
\end{aligned}
$$

Then

$$
\begin{aligned}
& \Delta G_{1}=\Delta G_{* \mathrm{OH}} \\
& \Delta G_{2}=\Delta G_{* \mathrm{O}}-\Delta G_{* \mathrm{OH}} \\
& \Delta G_{3}=\Delta G_{* \mathrm{OOH}}-\Delta G_{* \mathrm{O}} \\
& \Delta G_{4}=\Delta G_{\mathrm{O}_{2}}-\Delta G_{* \mathrm{OOH}}
\end{aligned}
$$

where $\Delta G_{\mathrm{O}_{2}}=\Delta G_{\mathrm{O}_{2}(\mathrm{~g})}$ is set equal to the experimental value of $4.92 \mathrm{eV}$.

To make a connection to experiment that uses the standard hydrogen electrode as a reference, the adsorption energies of intermediates are referenced to the reservoir species $\mathrm{H}_{2} \mathrm{O}$ and $\mathrm{H}_{2}$ as in the model of Man et al. ${ }^{42}$

$$
\begin{aligned}
& \Delta E_{* \mathrm{OH}}=E_{* \mathrm{OH}}-E_{*}-\left(E_{\mathrm{H}_{2} \mathrm{O}}-0.5 E_{\mathrm{H}_{2}}\right) \\
& \Delta E_{* \mathrm{O}}=E_{* \mathrm{O}}-E_{*}-\left(E_{\mathrm{H}_{2} \mathrm{O}}-E_{\mathrm{H}_{2}}\right) \\
& \Delta E_{* \mathrm{OOH}}=E_{* \mathrm{OOH}}-E_{*}-\left(2 E_{\mathrm{H}_{2} \mathrm{O}}-1.5 E_{\mathrm{H}_{2}}\right)
\end{aligned}
$$

where $E_{*}$ is the energy of the bare system. The free energy of any intermediate includes the zero-point vibrational and the entropic corrections (at 298.15 K, in the harmonic approximation; see Table S2)

$$
\Delta G=\Delta E+\Delta \mathrm{ZPE}-T \Delta S
$$


The approach of Man et al. is semiempirical in that while the adsorption and free energies of intermediates are calculated using DFT, the free energy for the overall process is set to the experimental value of $4.92 \mathrm{eV}$. In practice, Man et al. have demonstrated the approach to work well for the metal oxide systems, and thus we apply it here for OER on SWNT- and GRA-based systems. Thus, it is only necessary to calculate

$$
\begin{aligned}
& \Delta G_{* \mathrm{OH}}=G_{* \mathrm{OH}}-G_{*}-\left(G_{\mathrm{H}_{2} \mathrm{O}}-0.5 G_{\mathrm{H}_{2}}\right) \\
& \Delta G_{* \mathrm{O}}=G_{* \mathrm{O}}-G_{*}-\left(G_{\mathrm{H}_{2} \mathrm{O}}-G_{\mathrm{H}_{2}}\right) \\
& \Delta G_{* \mathrm{OOH}}=G_{* \mathrm{OOH}}-G_{*}-\left(2 G_{\mathrm{H}_{2} \mathrm{O}}-1.5 G_{\mathrm{H}_{2}}\right)
\end{aligned}
$$

The predicted theoretical OER overpotential then is

$$
\begin{aligned}
& \eta^{\text {OER }}=\max \left(\Delta G_{1}, \Delta G_{2}, \Delta G_{3}, \Delta G_{4}\right) / e-1.23 \mathrm{~V} \\
& \quad(\text { definition }) \\
& \approx \max \left(\Delta G_{2}, \Delta G_{3}\right) / e-1.23 \mathrm{~V} \\
& \quad \text { (since } 2 \text { nd or 3rd step dominates) } \\
& \approx \max \left(\Delta G_{2}, \quad 3.3 \mathrm{eV}-\Delta G_{2}\right) / e-1.23 \mathrm{~V}
\end{aligned}
$$

(due to scaling relation)

In practice, we used the exact definition in eq 19, but eqs 20 and 21 generally held true for all systems and sites.

The effect of an applied external potential $U$ and solution $\mathrm{pH}$ necessitates application of the appropriate corrections to the free energies

$$
\Delta G_{i}^{(U, \mathrm{pH})}=\Delta G_{i}-e U-k_{\mathrm{B}} T \cdot \ln 10 \cdot \mathrm{pH} \quad(i=1-4)
$$

and thus also the obtained overpotential. However, all results presented do not include such corrections (i.e., $U=0 \mathrm{~V}, \mathrm{pH}=$ 0 ), and thus our $\eta^{\mathrm{OER}}$ is actually $\eta^{\mathrm{OER}, 0}$. Note that the intermediates are identical in both alkaline and acidic media.

The DFT calculations were performed using the spinpolarized Perdew-Burke-Ernzerhof $(\mathrm{PBE})^{56}$ exchange-correlation functional supplemented with the dispersioncorrections of Grimme ${ }^{57}$ and the damping function of Becke and Johnson $^{58}$ (PBE-D3). The CP2K/Quickstep ${ }^{59-61}$ package was used for all calculations. Valence electrons were represented by the efficient molecularly optimized double- $\zeta$ with polarization basis sets (MOLOPT-SR-DZVP), ${ }^{62}$ while the ionic cores were described with the norm-conserving Goedecker-Teter-Hutter pseudopotentials. ${ }^{63-65}$ The DFT energies of $\mathrm{H}_{2}$ and $\mathrm{H}_{2} \mathrm{O}$ were calculated in an identical fashion. The basis set convergence of the binding energies of intermediates was examined by performing calculations with larger basis sets for a few selected systems and sites. Likewise, the basis set superposition errors were examined through use of the counterpoise correction and found to be small. The overall basis set incompleteness errors of the binding energies and thus also the derived attachment free energies of the intermediates with use of the MOLOPT-SR-DZVP basis set were estimated to be less than about $0.03 \mathrm{eV}$.

The truncation for the auxiliary plane wave basis set was 600 Ry. The self-consistent iterations were continued until the wave function was converged to $1 \times 10^{-6}$ Hartree. The criterion for geometry optimizations was that the maximum gradient be less than $4.5 \times 10^{-4}$ Hartree bohr $^{-1}=0.023 \mathrm{eV}$
$\AA^{-1}$. An identical setup had yielded good results in our group's previous studies of ORR/ $\mathrm{O}_{2}$ adsorption ${ }^{46}$ and HER. ${ }^{51,52}$

Pristine and nitrogen-doped SWNTs with various defects and nitrogen configurations based on modifications to the pristine SWNT were studied. The pristine system consisted of six units of the semiconducting, zigzag SWNT with chiral indices $(m, n)=(14,0)$ and contained 336 carbon atoms. A semiconducting nanotube was chosen as a good compromise for the purposes of the computational studies (ease of convergence with the efficient orbital transformation method, OT, rather than diagonalization). Moreover, semiconducting nanotubes are common in experimental samples. The SWNT was placed in a $40 \times 40 \times 25.64 \AA^{3}$ tetragonal supercell, with periodic boundary conditions. Only the $\Gamma$-point was considered. The diameter of the SWNT was $11.057 \AA$, and thus these lateral dimensions ensured a vacuum region of about 29 A separating the periodic replicas. The length of the SWNT was determined from a cell relaxation and corresponded to a virtually negligible expansion of $0.3 \%$ compared to the starting length of $25.56 \AA$ based on the experimental C$\mathrm{C}$ bond length of $1.42 \AA$ in graphene. The resulting $\mathrm{C}-\mathrm{C}$ bond lengths were 1.423 and $1.429 \AA$ in the axial ("a") and quasicircumferential ("qc") directions.

GRA was used for comparison with some literature results and also to test a limiting case of vanishing chirality and infinite diameter. The defective and/or N-doped GRA-based structures were generated in exact correspondence to the SWNTbased structures. The setup for the GRA calculations was identical to that used in ref 7. A traditional diagonalizationbased solver was used instead of OT. A total of 200 unoccupied states were added, and orbital occupations were smeared using the Fermi-Dirac method with an electronic temperature of $1000 \mathrm{~K}$. The pristine GRA consisting of 240 atoms was placed in the $x-y$ plane of a tetragonal supercell cell. The Martyna-Tuckerman method was used to disable periodicity in the $z$-direction. Cell relaxation in the $x-y$ plane was considered but found to cause minimal change. Thus, the experimental $\mathrm{C}-\mathrm{C}$ spacing of $1.42 \AA$ was fixed, and the dimensions of the cell were set to $24.595 \times 25.56 \times 30 \AA^{3}$.

Adsorption energies and free energies were determined on approximately 10 sites on most SWNT-based systems. Often the number of sites considered was less due to symmetry. Less extensive sampling was used for the GRA-based system where the main objective was to sample the most reactive sites.

The unit cells of the pristine SWNT and GRA model systems contained 336 and $240 \mathrm{C}$ atoms, respectively. Corresponding SWNT- and GRA-based nitrogen-doped/ defective model systems were created by replacing one to four $\mathrm{C}$ atoms by $\mathrm{N}$ atoms, creating one to two vacancies or a Stone-Wales rotation, introducing one to three $\mathrm{H}$ atoms, and/ or introducing an $\mathrm{O}$ atom. The resulting nitrogen-doped SWNT- and GRA-based model systems thus contained nitrogen dopings of approximately $0.3-1.2$ and $0.4-1.7 \%$, respectively.

To see the effect of distance from the defect and compare to the pristine case, on all SWNT- and GRA-based systems, OER at a distance site ("far" site) was modeled. This site's distance from the region of the $\operatorname{defect}(\mathrm{s})$ was approximately $10-15 \AA$.

\section{RESULTS AND DISCUSSION}

3.1. Structures of the Bare Systems. Shown in Figure $1 \mathrm{a}-\mathrm{k}$ are the bare pristine, $\mathrm{N}$-doped, and/or defective SWNTbased systems whose OER activity was modeled. Here, bare 

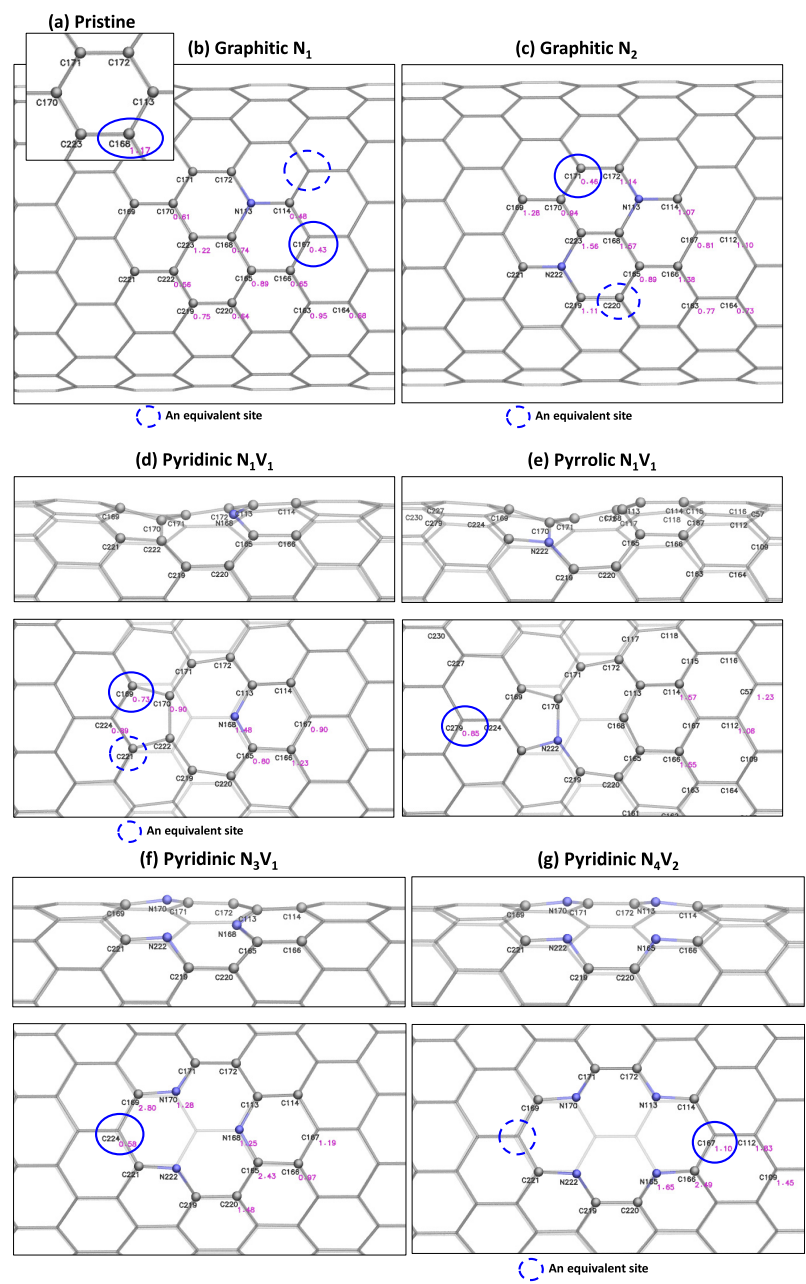

(h) Stones-Wales Pyrrolic $\mathrm{N}_{1 \mathrm{a}}$
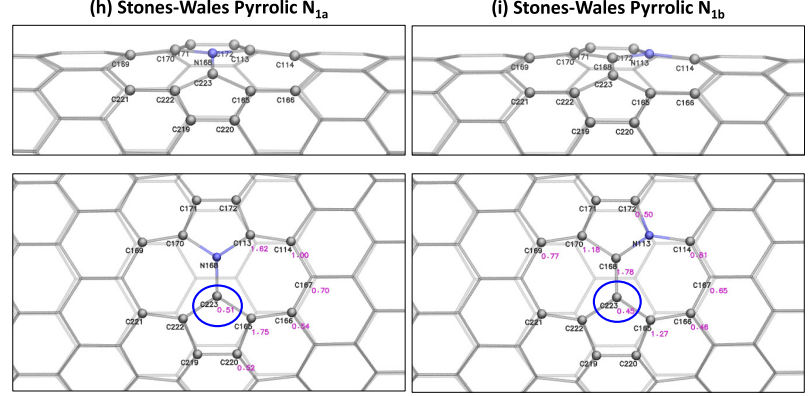

(j) Oxidized Pyridinic $\mathrm{N}_{1} \mathrm{~V}_{1} \mathrm{O}_{1}$
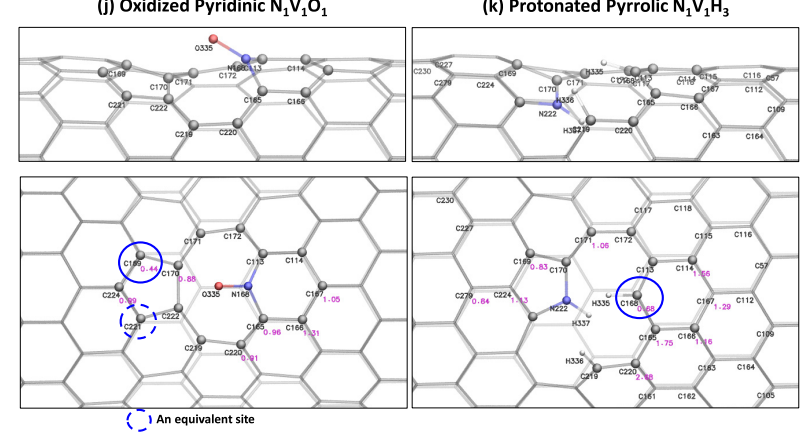

Figure 1. Structures of the model N-doped and/or defective SWNTbased systems (top views are shown; in addition, the upper panels of subfigures $(\mathrm{d}-\mathrm{k})$ show the side views). Atoms in the vicinity of the studied sites are shown as spheres (carbon, gray; nitrogen, blue; oxygen, red; hydrogen, white) and labeled. The calculated overpotential $\eta^{\mathrm{OER}}$ (in V) at a studied site is also shown. For each system,
Figure 1. continued

the optimal site for OER is circled. The corresponding information for the GRA-based systems is shown in Figure S1 of the SI.

means the surface prior to addition of any adsorbate. The active region in the vicinity of the defect or $\mathrm{N}$ atom(s) is shown. To examine the effects of curvature and chirality in a limiting case, graphene analogs of the 11 "main" (and seven "additional") SWNT-based structures were constructed (see Figure S1; note that many of the details pertaining to the GRAbased systems are presented in the SI). In the GRA-based systems, the mechanisms were the same and results broadly similar.

The panels of Figure 1 present the top (and where helpful, the side) views of the 11 main SWNT-based systems. Based on the pristine SWNT system shown in panel (a), these include systems with one or two graphitically substituted $\mathrm{N}$ atoms (panels (b) and (c)); one to four $\mathrm{N}$ atoms in pyridinic or pyrrolic roles, which require also single or double vacancies (panels $(\mathrm{d}-\mathrm{g})$ ); and a Stone-Wales rotation of two $\mathrm{C}$ atoms together with a $\mathrm{N}$ atom in a pyrrolic role in two different locations (panels (h) and (i)). The graphitic and pyridinic nitrogens were both members of hexagonal rings, with the latter being coordinated by only two carbon atoms, while a pyrrolic nitrogen was a member of a pentagonal ring. Thus, while a graphitic nitrogen may be obtained by substitution, a pyridinic nitrogen requires at least a single vacancy. A pyrrolic nitrogen may be obtained either with a vacancy or in the presence of a Stone-Wales defect (see, e.g., refs 66-68). The effect of oxygen codoping of the pyridinic nitrogen was also considered (panel $(j))$, as was protonation of pyrrolic nitrogen (panel (k)).

All of these nitrogen functionalities have been observed via $\mathrm{X}$-ray photoelectron spectroscopy characterizations of $\mathrm{N}$ doped CNTs and in OER experiments (see, e.g., ref 36 see also Table S3 and the accompanying discussion). The actual structures shown in Figure 1a-k are well supported by, and in some cases modeled on, the experimental and theoretical work of Arenal et al. ${ }^{67}$ who performed experimental high-resolution transmission electron microscopy and electron energy-loss spectroscopy observations and DFT simulations of defective and N-doped $(22,0)$ SWNTs, including systems containing stable graphitic, pyridinic, and Stone-Wales pyrrolic nitrogen functionalities. Formation energies of the bare model systems and partial charges in the region of the active site are discussed in the SI. Note that the deciding factor in determining whether a certain defect or nitrogen functionality exists is the experimental observations, rather than the formation energies, since the structures are often produced in nonequilibrium processes and stabilized by barriers preventing reversion to the pristine structures.

The additional systems could be divided into two classes: (1) those with vacancies or the Stone-Wales rotation but without $\mathrm{N}$ atoms (three systems; chosen to disentangle the effects of $\mathrm{N}$-doping from lattice distortion effects) and (2) those with vacancies and pyridinic $\mathrm{N}$ atoms and passivation of the $\mathrm{C}$ or $\mathrm{N}$ vertex atoms by $\mathrm{H}$ atoms (four systems; to examine the effect of protonation). More discussion of the additional systems can be found in the SI. The labeling nomenclature is the same as in an earlier study. ${ }^{69}$ For example, a system with graphitic substitution can be labeled as $\mathrm{N}_{i}$, and in general, a system with vacancies, some $\mathrm{N}$-doping, passivation by $\mathrm{H}$ 
Table 1. OER Modeling Results for SWNT-Based and GRA-Based Systems: Lowest Calculated Overpotential $\left(\eta^{\text {OER }}\right)$, Potential-Determining Step (PDS), and the Site's Neighbor Number (nn) Relative to the Nearest Defect ${ }^{a}$

\begin{tabular}{|c|c|c|c|c|c|c|c|}
\hline \multirow{2}{*}{\multicolumn{2}{|c|}{ system }} & \multicolumn{3}{|c|}{ SWNT-based } & \multicolumn{3}{|c|}{ GRA-based } \\
\hline & & $\eta^{\mathrm{OER}}(\mathrm{V})$ & PDS & $\mathrm{nn}$ & $\eta^{\mathrm{OER}}(\mathrm{V})$ & PDS & $\mathrm{nn}$ \\
\hline \multicolumn{8}{|c|}{ Main Set of 11 Systems } \\
\hline (a) & pristine & 1.17 & 3 & na & 1.37 & 1 & na \\
\hline (b) & graphitic $\mathrm{N}_{1}$ & 0.43 & 2 & 2 & 0.58 & 1 & 3 \\
\hline (c) & graphitic $\mathrm{N}_{2}$ & 0.46 & 3 & 2 & 0.70 & 3 & 3 \\
\hline (d) & pyridinic $\mathrm{N}_{1} \mathrm{~V}_{1}$ & 0.73 & 3 & 2 & 0.64 & 3 & 3 \\
\hline (e) & pyrrolic $\mathrm{N}_{1} \mathrm{~V}_{1}$ & 0.85 & 3 & 3 & $b$ & & \\
\hline (f) & pyridinic $\mathrm{N}_{3} \mathrm{~V}_{1}$ & 0.58 & 2 & 2 & 0.51 & 2 & 2 \\
\hline (g) & pyridinic $\mathrm{N}_{4} \mathrm{~V}_{2}$ & 1.10 & 3 & 2 & 0.62 & 2 & 2 \\
\hline (h) & Stone-Wales pyrrolic $\mathrm{N}_{1 a}$ & 0.51 & 3 & 0 & 0.64 & 3 & 0 \\
\hline (i) & Stone-Wales pyrrolic $\mathrm{N}_{1 b}$ & 0.45 & 2 & 0 & 0.43 & 3 & 2 \\
\hline (j) & oxidized pyridinic $\mathrm{N}_{1} \mathrm{~V}_{1} \mathrm{O}_{1}$ & 0.44 & 3 & 2 & 0.60 & 3 & 3 \\
\hline (k) & protonated pyrrolic $\mathrm{N}_{1} \mathrm{~V}_{1} \mathrm{H}_{3}$ & 0.68 & 3 & 1 & 0.93 & 3 & 1 \\
\hline
\end{tabular}

Additional Systems

Set 1:

$\begin{array}{ll}(\mathrm{l}) & \mathrm{V}_{1} \\ (\mathrm{~m}) & \mathrm{V}_{2} \\ (\mathrm{n}) & \text { Stone-Wales }\end{array}$

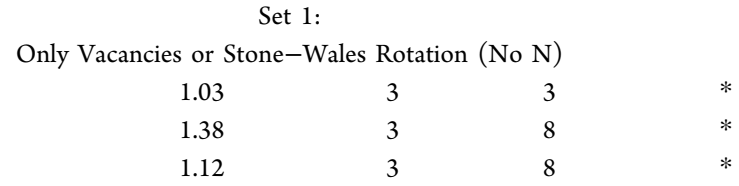

Set 2: Pyridinic $\mathrm{N}_{1,3} \mathrm{~V}_{1}$ -

\begin{tabular}{|c|c|c|c|c|}
\hline (o) & protonated pyridinic $\mathrm{N}_{1} \mathrm{~V}_{1} \mathrm{H}_{1}$ & 0.95 & 3 & 2 \\
\hline (p) & protonated pyridinic $\mathrm{N}_{1} \mathrm{~V}_{1} \mathrm{H}_{3}$ & 0.63 & 3 & 1 \\
\hline (q) & one protonated pyridinic $\mathrm{N}_{3} \mathrm{~V}_{1} \mathrm{H}_{1}$ & 1.09 & 3 & 2 \\
\hline (r) & three protonated pyridinic $\mathrm{N}_{3} \mathrm{~V}_{1} \mathrm{H}_{3}$ & 0.67 & 3 & 1 \\
\hline
\end{tabular}

${ }^{a}$ Bold or italic text corresponds to those systems found to be OER highly active (defined here as a system/site with $\left.\eta^{\text {OER }}<0.50 \mathrm{~V}\right)$ or active $\left(\eta^{\text {OER }}\right.$ $=0.50-0.59 \mathrm{~V})$, while normal text corresponds to inactive systems $\left(\eta^{\mathrm{OER}} \geq 0.60 \mathrm{~V}\right)$. “*” marks those systems for which OER calculations were not performed. The labels $(\mathrm{a}-\mathrm{k})$ are shown for easy reference to the SWNT- and GRA-based structures shown in Figures 1 and S1, respectively, where the lowest $\eta^{\text {OER }}$ are circled. ${ }^{b}$ This system (Figure S1, panel (e)) differs from the one directly above (Figure S1, panel (d)) by merely a clockwise rotation of $120^{\circ}$ and thus is essentially identical.

atoms, and attached $\mathrm{O}$ atoms can be labeled as $\mathrm{N}_{i} \mathrm{~V}_{j} \mathrm{H}_{k} \mathrm{O}_{v}$ where $i, j, k$, and $l$ are the number of $\mathrm{C}$ to $\mathrm{N}$ atom replacements, remaining vacancy sites, protonation by attached $\mathrm{H}$ atoms, and attached $\mathrm{O}$ atoms, respectively. When vacancies are present, it is also necessary to indicate whether $\mathrm{N}$ atoms are in a pyridinic or pyrrolic role. For systems with graphitic $\mathrm{N}$ or Stone-Wales systems, only the first index is required. Protonation may occur at vertex $\mathrm{N}$ or $\mathrm{C}$ atoms (note that the presence of vertex atoms requires one or more vacancies). Systems may contain a single defect (simple defect, e.g., the $\mathrm{N}_{1}$ system) or multiple defects (complex defect, e.g., the pyridinic $\mathrm{N}_{1} \mathrm{~V}_{1}$ system). Except in the case of the graphitic $\mathrm{N}_{2}$ system, systems with a complex defect always had the multiple defects adjacent.

Upon introducing defects and/or nitrogen atoms into the carbon lattices, known reconstructions and distortions were observed. The SWNT lattice suffered some distortion when vacancies were introduced: a reconstruction leading to formation of a pentagon and an indentation in the systems with $\mathrm{N}_{1} \mathrm{~V}_{1}$ (panels (d) and (e)); flap opening in the systems with double vacancies and/or multiple $\mathrm{N}$ atoms, $\mathrm{N}_{3} \mathrm{~V}_{1}$ and $\mathrm{N}_{4} \mathrm{~V}_{2}$ (panels (f) and (g)); and radial upward puckering in the presence of a Stone-Wales defect (panels (h) and (i)). Note that the Stone-Wales systems exhibit the typical 7-5-5-7 ring structures in place of the standard hexagonal lattice. In the absence of $\mathrm{N}$ atoms, most of these distortions were still present. Protonation of the vertex atoms of the systems shown in panels (d) and (e) prevented the reconstruction, leading to pentagon formation. Likewise, replacement of all $\mathrm{C}$ vertex atoms by $\mathrm{N}$ atoms when creating the pyridinic $\mathrm{N}_{3} \mathrm{~V}_{1}$ system prevented the reconstruction. The corresponding GRA-based analog (see Figure S1) of an SWNT-based system underwent a similar reconstruction to that observed in the SWNT-based systems. While the GRA-based systems did not exhibit the outof-plane distortions (e.g., flap opening or dips), they were highly distorted upon introduction of the adsorbates (see SI).

3.2. OER Overpotentials. Shown also in Figure 1 are the overpotential $\eta^{\mathrm{OER}}$ values (in $\mathrm{V}$ ) obtained at various sites. The best performing site (i.e., the $\mathrm{C}$ atom with the lowest overpotential) and its symmetry equivalents, if any, are indicated. The region further away from the active region, with the far site, is not shown; however, it was usually similar to the pristine system value. The most active site often possessed a small-to-moderate partial charge and was usually a second or third neighbor of the dopant $\mathrm{N}$ atom. The first or immediate neighbors of the dopant $\mathrm{N}$ atom had the most positive partial charge and stronger attachment energies, which often resulted in an increase in the site's overpotential by the Sabatier principle. This replicates the observation made in an earlier OER DFT study on N-doped graphene nanoribbons. ${ }^{53}$

Note that no overpotential value is shown if the reaction at that site was a side reaction not contributing to the four-step OER. We observed two possible side reactions: the breaking of $\mathrm{OOH}$ and the formation of adsorbates at two sites $a$ and $b$, that 
is, ${ }^{* a} \mathrm{OOH} \rightarrow{ }^{* a} \mathrm{O}+{ }^{* b} \mathrm{OH}$; or rarely, the breaking of $\mathrm{OH}$, that is, ${ }^{* a} \mathrm{OH} \rightarrow{ }^{* a} \mathrm{O}+{ }^{* b} \mathrm{H}$. Note that these side reactions only occurred in a few cases, mainly on the systems containing vacancies, in the active region in the vicinity of the vacancy (or vacancies). This is likely due to the stronger electric fields present given the larger partial charges in those systems. Such side reactions may result in increased coverage by $* \mathrm{OH}$ or $* \mathrm{O}$ and possibly increased reactivity at other sites. We are in the process of examining the possible cooperative effect of such nonzero coverage. This work will appear in a future publication. Since the adsorbates were in practice negatively charged (due to donation of electronic charge from elsewhere in the overall neutral systems), adsorption and reaction at $\mathrm{C}$ sites were overwhelmingly preferred. Only in one or two cases were adsorption and reaction at an $\mathrm{N}$ site observed. Moreover, the analysis showed that the activity at the $\mathrm{N}$ sites was not favorable.

From Table 1 it is seen that the best performing SWNTbased systems were the graphitic nitrogen systems ( 0.43 and $0.46 \mathrm{~V}$, Figure $1 \mathrm{~b}, \mathrm{c})$, the oxidized pyridinic nitrogen system $(0.44 \mathrm{eV}$; Figure $1 \mathrm{j})$, and the Stone-Wales pyrrolic nitrogen systems $(0.45$ and $0.51 \mathrm{~V}$, Figure $1 \mathrm{~h}, \mathrm{i})$. The ordering of the GRA-based systems was different. The graphitic nitrogen systems exhibited lower reactivity due to weaker attachment energies of the intermediates. The best performing system was the Stone-Wales pyrrolic nitrogen system (0.43 V, Figure S1i). Next in order of activity was the pyridinic nitrogen $\mathrm{N}_{3} \mathrm{~V}_{1}$ system (0.51 V, Figure S1f). The effect of codoping with oxygen warrants particular discussion. Considering the SWNTbased systems, the oxidized pyridinic nitrogen system (overpotential of $0.44 \mathrm{eV}$; Figure $1 \mathrm{j}$ ) exhibits much improved performance over the unoxidized pyridinic nitrogen system (overpotential of $0.73 \mathrm{eV}$; Figure 1d). Other researchers have also found that $\mathrm{O}$-doped or $\mathrm{N}, \mathrm{O}$-codoped nanotubes result in good OER performance. ${ }^{28,35}$

3.3. OER Energy Step Diagrams and Structures of Intermediates. Based on the attachment energies, the OER free energy step diagrams of the four-step OER process $\left(\Delta G_{1-4}\right)$ were constructed. Figures 2-34 present the step diagrams for the three best performing SWNT-based systems and sites: graphitic $N_{1}$, Stone-Wales pyrrolic $N_{1 b}$, and oxidized pyridinic $\mathrm{N}_{1} \mathrm{~V}_{1} \mathrm{O}_{1}$. (The step plots for the SWNT-based pristine, graphitic $N_{2}$, and pyridinic $\mathrm{N}_{3} \mathrm{~V}_{1}$ and also for all the corresponding GRA-based systems are shown in Figures $\mathrm{S}_{2}-$ S14 and S2-S7, respectively.) The PDS (most often the second or third step) and $\eta^{\mathrm{OER}}(1.17 \mathrm{~V}$ for the pristine system and about $0.4-0.5 \mathrm{~V}$ for the best performing systems) are also shown, as are structures and sometimes the C-site's outward radial movement due to change from $\mathrm{sp}^{2}$ to $\mathrm{sp}^{3}$ hybridization upon formation of the covalent bond to the adsorbate atom.

As mentioned, with a few exceptions, the mechanisms and geometries of the corresponding intermediates were similar on all the SWNT-based systems. Both $\mathrm{OH}$ and $\mathrm{OOH}$ attach via a single bond to the $\mathrm{C}$ atom ("top" or " $\mathrm{t}$ " site adsorption), whose change in coordination and hybridization causes it to rise from the surface by about $0.4-0.5 \AA$ for both adsorbates. The nearly identical change of the underlying structure (in most cases) in both $\mathrm{OH}$ and $\mathrm{OOH}$ adsorption helps rationalize the nearly perfect scaling observed between these intermediates' adsorption energies (see below). $\mathrm{OH}$ attaches vertically, while $\mathrm{OOH}$ attaches in a vertical fashion but with a structure reminiscent of peroxide.

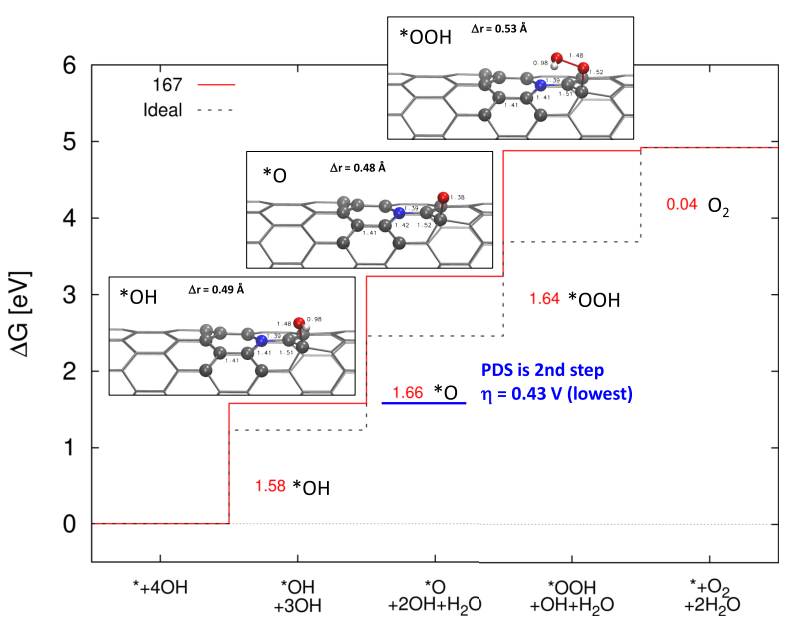

Figure 2. Calculated OER free energy step diagram (red line) for the graphitic $\mathrm{N}_{1}-\mathrm{SWNT}$ system for the site shown circled in Figure $1 \mathrm{~b}$. The dotted black line shows for comparison the step diagram for the ideal case where each step is $1.23 \mathrm{eV}$. The insets show the structures and some interatomic distances of the $* \mathrm{OH}, * \mathrm{O}$, and $* \mathrm{OOH}$ intermediates, and the $\Delta r$ values are the radial displacements of the underlying $\mathrm{C}$ atom(s) upon adsorption of the intermediate. The potential-determining step (PDS) and the corresponding overpotential $\eta^{\mathrm{OER}}$ are also indicated. For this figure and the subsequent four figures, the corresponding GRA information is shown in Figures S5-S10 of the SI.

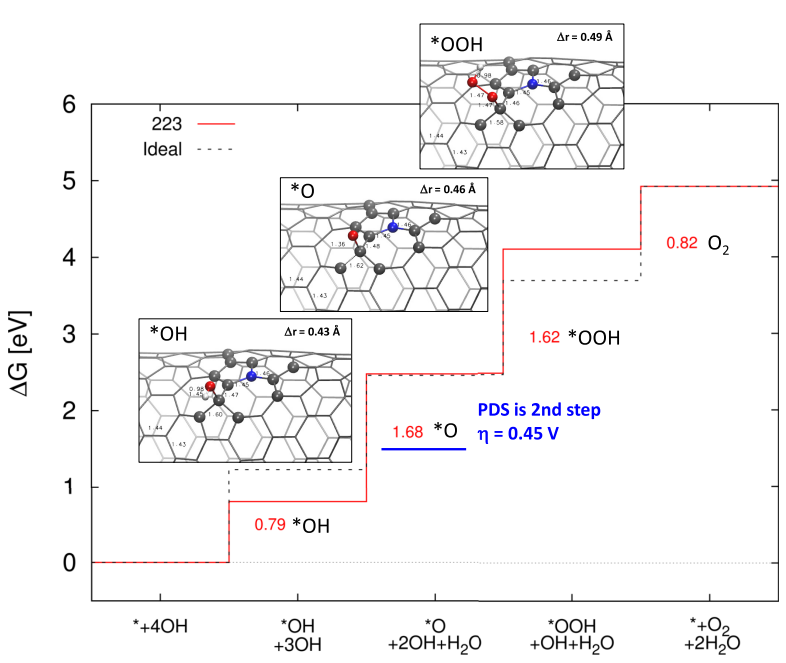

Figure 3. Calculated OER free energy step diagram for the StoneWales pyrrolic $\mathrm{N}_{1 b}-\mathrm{SWNT}$ system for the site shown circled in Figure 1i. Otherwise similar to Figure 2.

While $\mathrm{OH}$ and $\mathrm{OOH}$ undergo top site adsorption, $\mathrm{O}$ can also adsorb on a "bridge" site, which on our zigzag SWNTbased systems can be an "axial bridge" site ("ba" site) or a quasicircumferential bridge site ("bqc" site). Note that on the GRA-based systems, the two directions are equivalent (although the Stone-Wales defective systems do impose an effective directional or axial symmetry), and thus a bridge site in the GRA-based is labeled simply as a "b" site. In general, the GRA-based systems' behavior was very similar in terms of structures of intermediates. However, as mentioned, the attachment energies were usually weaker.

3.4. OER Scaling Relation. As discussed by Hessels et al., ${ }^{54}$ Man et al., ${ }^{42}$ and others, a scaling relation in adsorption energies or free energies, $\Delta G_{* \mathrm{OOH}}=\Delta G_{* \mathrm{OH}}+3.2 \pm 0.2 \mathrm{eV}$, $^{54}$ 


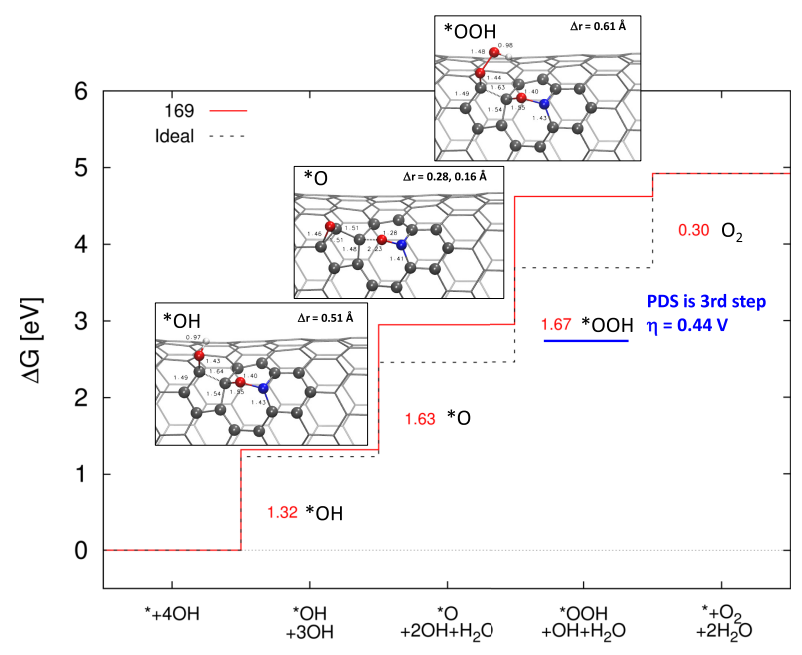

Figure 4. Calculated OER free energy step diagram for the oxidized pyridinic $\mathrm{N}_{1} \mathrm{~V}_{1} \mathrm{O}_{1}-\mathrm{SWNT}$ system for the site shown circled in Figure 1j. Otherwise similar to Figure 2.

between related intermediate chemical species binding to the same site can often be expected. We observed a nearly perfect scaling of the energy of the first and third intermediates, with less than $1 \%$ deviation in the slope or intercept of the linear relation $\Delta G_{* \mathrm{OOH}}=\Delta G_{* \mathrm{OH}}+3.3 \mathrm{eV}$, both when all sites were plotted and when just the best sites on each system were plotted, as seen in Figure 5a,b for SWNT- and GRA-based systems (see the SI for additional systems and sites). The very few systems and sites with somewhat larger deviations (not included in the fits) occurred in the few rare cases where an $\mathrm{N}$ atom site served as the OER site (the predicted overpotential of such a site was high) or in the GRA-based systems, which contained a vacancy and thus more structural flexibility since relative changes in geometry and chemical environment of a site of the $* \mathrm{OOH}$ intermediate compared to the $* \mathrm{OH}$ intermediate can cause deviations in the scaling relation.

3.5. Attachment Energies of $* \mathrm{OH}$ and $* 0$ Intermediates Resulting in High Activity: Examination of Energy Clustering. The effect of $\mathrm{N}$-doping is to induce small positive charges in the neighboring $\mathrm{C}$ atoms of about 0.1e (Hirshfeld population analysis; see Table S3), allowing them to better bond the initial intermediate, $* \mathrm{OH}$ (and often also the subsequent $* \mathrm{O}$ and $* \mathrm{OOH}$ intermediates since this depends also on scaling relations ${ }^{42}$ ). This occurs since the intermediates have small negative partial charges donated by the carbon system. Recall that the modeling is performed in an overall neutral cell, thus simulating electrochemistry only in an approximate sense, with the assumption that the negative charge from the $\mathrm{OH}^{-}$is instantaneously conducted away. However, there are still small negative partial charges on the intermediate moieties. Since Sabatier's principle requires an attachment energy for all intermediates that is not overly attractive (i.e., a spacing of $1.23 \mathrm{eV}$ between the attachment free energies of subsequent intermediates), sites other than the ones with the largest positive partial charge may be more efficient for the overall OER reaction.

Owing to the scaling relation, only two of the energies of the three intermediates are independent. The analysis is facilitated by choosing the energies of the $* \mathrm{OH}$ and $* \mathrm{O}$ intermediates. Even better is selection of the descriptor energy, the linear combination $\Delta G_{*_{\mathrm{O}}}-\Delta G_{*_{\mathrm{OH}}}$ and the energy of the first intermediate, $\Delta G_{* \mathrm{OH}}$. Figure $S 13$ presents a plot of $\Delta G_{* \mathrm{OH}}$ as a (a)

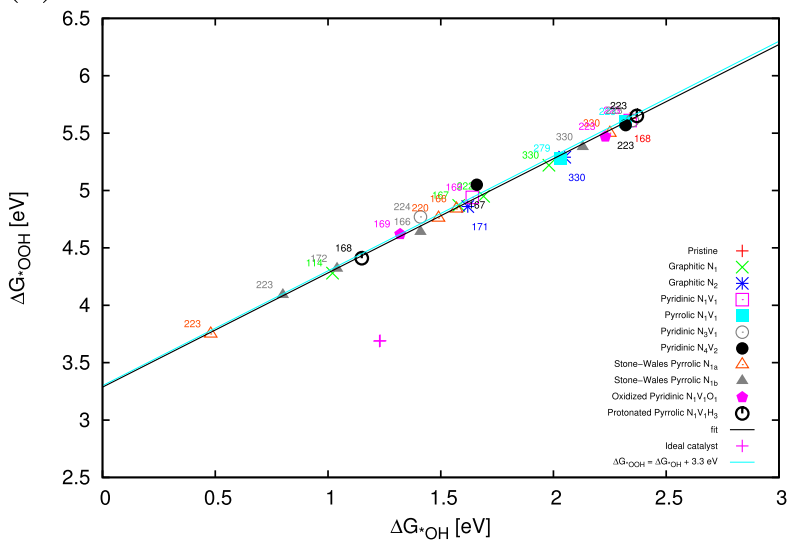

(b)

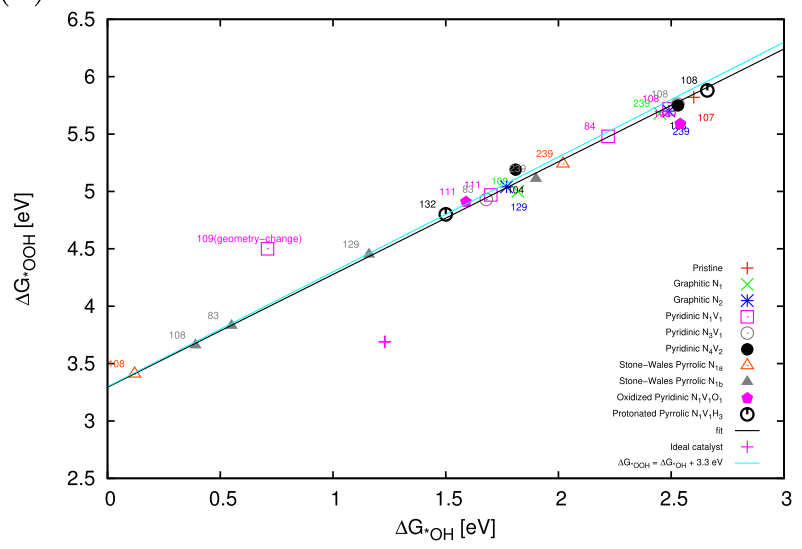

Figure 5. Energy scaling in (a) SWNT-based systems (11 main systems) and (b) GRA-based systems (10 main systems). Only the best and far sites are shown for each system. It is seen that $\Delta G_{* \mathrm{OOH}}=$ $\Delta G_{*_{\mathrm{OH}}}+3.3 \mathrm{eV}$ to an excellent approximation. See text for details.

function of $\Delta G_{*_{\mathrm{O}}}-\Delta G_{*_{\mathrm{OH}}}$. It is seen that for both SWNTbased and GRA-based systems, the "highly active" systems are clustered in the box defined by $\Delta G_{*_{\mathrm{O}}}-\Delta G_{* \mathrm{OH}}=1.65 \pm 0.14$ $\mathrm{eV}, \Delta G_{* \mathrm{OH}}=1.06 \pm 0.69 \mathrm{eV}$. The second condition indicates that the intermediate $* \mathrm{OH}$ cannot be too weakly bound (points for the weakly bonding systems/sites, including the pristine system and far sites, are located at the upper left regions of the plots, at more positive $\left.\Delta G_{* \mathrm{OH}}\right)$. Nevertheless, there is a significant variation possible in $\Delta G_{* \mathrm{OH}}$, which can still result in high activity. The range in the energy difference as defined in the descriptor, however, is more restrictive and therefore predictive of performance (thus the descriptor is used in presenting the activity graphically via a volcano plot; see below).

Compared to the nanotube-based systems, the main qualitative difference in the graphene-based systems was the lack of an axis, which led to more symmetry and often altered the reconstruction of the bare systems, as discussed above. The adsorption energies were usually about $10-20 \%$ less attractive, often resulting in a lowered OER reactivity. The stronger adsorption in the nanotube-based systems compared to the corresponding graphene-based systems can be attributed to rehybridization and polarization/shift of electronic density to the nanotube's outer surface that occurs when graphene is rolled to form the nanotube. Furthermore, the strength of adsorption of a number of species on the nanotube outer wall 
has been found to be correlated with increasing nanotube curvature (see, e.g., refs 46 and 70-72).

3.6. OER Volcano Plots. The OER activity in the form of the overpotentials on the SWNT- and GRA-based systems was presented in Table 1. Graphical representations of the OER activity on the SWNT- and GRA-based main systems are shown in Figure 6a,b (five additional SWNT-based systems

(a) SWNT-based systems

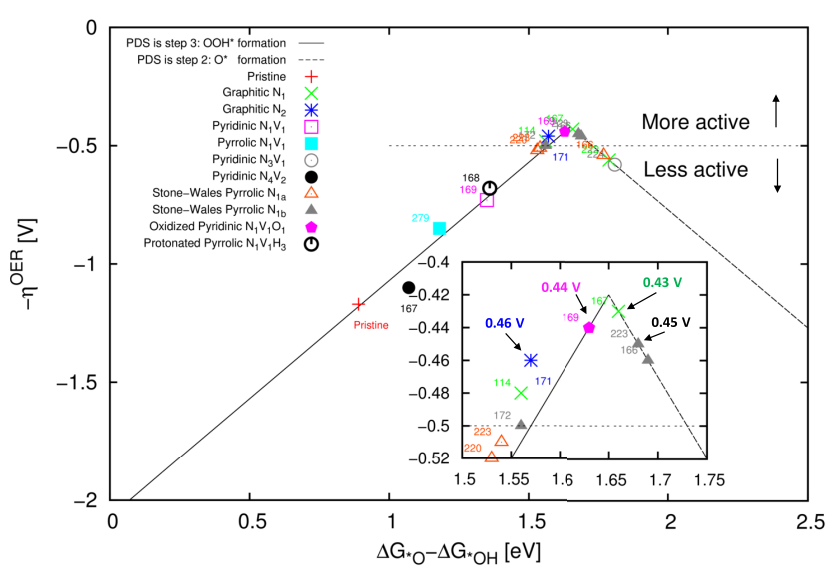

(b) GRA-based systems

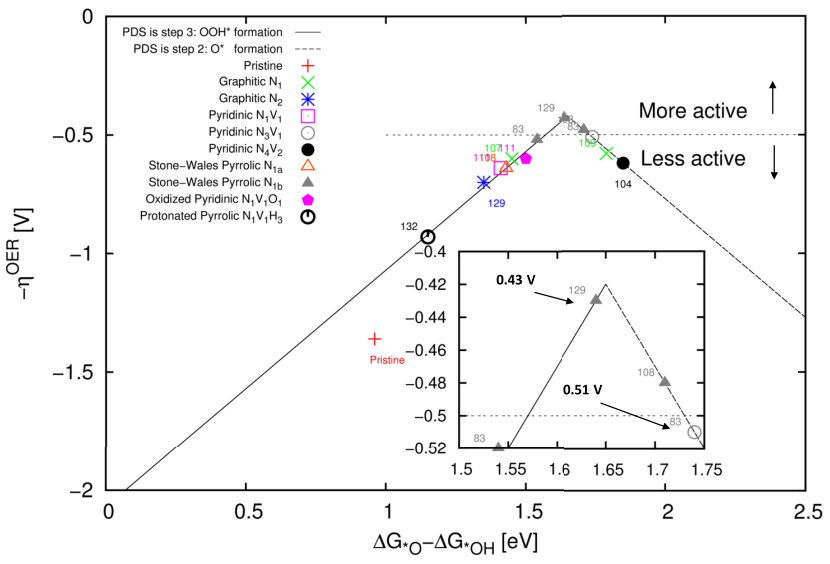

Figure 6. Volcano plots for OER on (a) SWNT-based systems (11 main systems) and (b) GRA-based systems (10 main systems). The inset shows the region of best performance. Only the best site or sites are shown for each system (multiple nonequivalent sites existed because in a few cases more than one site per system exhibited good OER performance in the form of a low overpotential, i.e., $\eta^{\text {OER }} \lesssim 0.5$ V). The most highly active systems/sites are highlighted.

exploring defects without the presence of nitrogen or protonation of pyridinic $\mathrm{N}$ sites are shown in Figure S14; these modifications worsen the activity). The best performing systems are seen in the insets of the volcano plots. While neither $\Delta G_{*_{\mathrm{OH}}}$ nor $\Delta G_{*_{\mathrm{O}} \mathrm{O}}$ is a predictor of good activity, the descriptor, $\Delta G_{2}=\Delta G_{* \mathrm{O}}-\Delta G_{* \mathrm{OH}}$, which is plotted on the abscissa, is a good predictor of high activity. For example, all well-performing systems have $\Delta G_{2} \sim 1.65 \pm 0.14 \mathrm{eV}$.

\section{OUTLOOK}

The scaling relation of the single-site WNA mechanism ${ }^{54}$ between the $* \mathrm{OH}$ and $* \mathrm{OOH}$ intermediates is found to hold for the SWNT- and GRA-based systems we have considered, and our best calculated OER overpotentials are near the peak of the volcano plot $(\sim 0.42 \mathrm{~V})$ predicted by this relation. Thus, although the nanocarbon-based systems in this work may fulfill three of the four criteria outlined in the Introduction (composed of earth-abundant materials, ease of manufacture, and stability, as determined in experiments), the additional criterion of a much lower overpotential remains a challenge. This finding is in line with previously published work, either experimental or theoretical OER studies of the metal-free nanocarbon systems, which shows similar limiting behavior in that calculated or measured overpotentials less than $0.3-0.4 \mathrm{~V}$ have not been obtained (see Table S1).

The search for an OER catalyst with much improved performance is ongoing. Some recent examples are attempts to favorably tune the relative free energies of intermediates with the use of dopant or codopant atoms (sometimes $\mathrm{Au}$ ) in metal oxides $^{73,74}$ and nanocarbon systems, ${ }^{75}$ possibly achieving high performance by tuning both the intrinsic activity while simultaneously raising the geometric activity. ${ }^{76} \mathrm{~A}$ second possible approach to "break the scaling relation" and substantially reduce the overpotential would be to construct a catalyst with greater electronic or structural flexibility. The low overpotentials of 0.21 and $0.32 \mathrm{eV}$ obtained in calculations on two cluster models of the biological oxygen-evolving complex in photosystem II are attributed to the structural flexibility and also the electronic flexibility in the form of multiple accessible oxidation states of metal atoms in the Mncontaining cluster. ${ }^{45}$ The recent work of one of us on covalent functionalization of CNTs with active groups chelating an $\mathrm{Ni}$ atom active site is a step in the direction of utilizing the torsional flexibility of the functional groups. ${ }^{19}$ Yet a third alternative is design of a catalyst where OER can occur via a two-site ROC mechanism, ${ }^{54}$ see, for example, ref 12 . The outlined approaches may allow realization of an electrocatalyst, which goes beyond the scaling-based limitation. Such a large reduction in overpotential is highly desirable since it can improve catalyst performance by many orders of magnitude. ${ }^{4}$

\section{CONCLUSIONS}

We have used the thermodynamic model in conjunction with DFT attachment energies of intermediates to perform an extensive examination of active OER sites in SWNT and GRA systems with various nitrogen-doping functionalities (graphitic, pyridinic, or pyrrolic) and defect structures. Introduction of $0.3-1 \%$ nitrogen, sometimes in conjunction with simple defects such as vacancies and Stone-Wales rotations, led to substantial improvement in the OER activity of the initially relatively inactive pristine carbon systems. For example, in the case of the SWNT-based systems, while the pristine system yielded a predicted overpotential of $1.17 \mathrm{~V}$, the same system doped with a single graphitic nitrogen atom resulted in a nearest-neighbor activated carbon atom with a predicted overpotential of $0.43 \mathrm{~V}$. Codoping with oxygen, via oxidation of a pyridinic nitrogen, also yielded good results (overpotential of $0.44 \mathrm{~V}$ ), as did the Stone-Wales system with a pyrrolic nitrogen atom $(0.45 \mathrm{~V})$. The graphene-based systems yielded similar though often somewhat worse results. We further confirmed that the four-step single-site WNA mechanism ${ }^{54}$ was appropriate for modeling OER on these systems, with in most cases the second step, formation of $* \mathrm{O}$, or the third step, formation of $* \mathrm{OOH}$, being the potential-determining step.

Following the initial screening results of this study, our companion DFT study of OER kinetic barriers on $\mathrm{N}$-doped SWNTs with inclusion of explicit solvent ${ }^{77}$ shows that 
inclusion of explicit solvent, while essential for determining kinetic barriers, does not qualitatively alter the thermodynamics (e.g., OER mechanism, structures and attachment energies of intermediates, potential-determining step, or active site). However, the OER kinetic barriers in systems/catalytic sites where the thermodynamics analysis predicts similar activity and overpotentials may occasionally differ, ${ }^{77}$ and the effective overpotentials including the kinetic barriers may be altered. Thus, while the thermodynamic approach is useful for screening, it should be followed by calculations including explicit solvent and kinetic barriers.

\section{ASSOCIATED CONTENT}

\section{S Supporting Information}

The Supporting Information is available free of charge on the ACS Publications website at DOI: 10.1021/acs.jpcc.8b08519.

Figures S1-S14 and Tables S1-S4 and associated discussion; table of selected literature results for OER catalysts in alkaline medium; additional details pertaining to methods used; supporting results and discussion (structures of the bare GRA-based systems and partial charges and formation energies of all systems, OER energy step diagrams and structures of intermediates of additional SWNT-based systems and all GRA-based systems, energy scaling/clustering and correlation to high activity, and OER volcano plot showing additional SWNT-based systems) (PDF)

\section{AUTHOR INFORMATION}

\section{Corresponding Author}

*E-mail: garold.murdachaew@aalto.fi.

ORCID $\odot$

Garold Murdachaew: 0000-0001-6958-6765

Kari Laasonen: 0000-0002-4419-7824

Notes

The authors declare no competing financial interest.

\section{ACKNOWLEDGMENTS}

The work was supported by the Academy of Finland through its Centres of Excellence Program (project no. 251748) and by the School of Chemical Engineering, Aalto University. We acknowledge the computing resources provided by Finland's CSC-IT Center for Scientific Computing. G.M. thanks Nico Holmberg, Olli Pakkanen, Dr Mohammad Tavakkoli, and Fatemeh Davodi for discussions.

\section{REFERENCES}

(1) Lewis, N. S.; Nocera, D. G. Powering the Planet: Chemical Challenges in Solar Energy Utilization. Proc. Natl. Acad. Sci. U.S.A. 2006, 103, 15729-15735.

(2) Armaroli, N.; Balzani, V. The Hydrogen Issue. ChemSusChem 2011, 4, 21-36.

(3) Cook, T. R.; Dogutan, D. K.; Reece, S. Y.; Surendranath, Y.; Teets, T. S.; Nocera, D. G. Solar Energy Supply and Storage for the Legacy and Nonlegacy Worlds. Chem. Rev. 2010, 110, 6474-6502.

(4) Seh, Z. W.; Kibsgaard, J.; Dickens, C. F.; Chorkendorff, I.; Nørskov, J. K.; Jaramillo, T. F. Combining Theory and Experiment in Electrocatalysis: Insights into Materials Design. Science 2017, 355, No. eaad4998.

(5) Cheng, F.; Chen, J. Metal-Air Batteries: From Oxygen Reduction Electrochemistry to Cathode Catalysts. Chem. Soc. Rev. 2012, 41, 2172-2192.
(6) Reier, T.; Oezaslan, M.; Strasser, P. Electrocatalytic Oxygen Evolution Reaction (OER) on $\mathrm{Ru}, \mathrm{Ir}$, and Pt Catalysts: A Comparative Study of Nanoparticles and Bulk Materials. ACS Catal. 2012, 2, 1765-1772.

(7) Tavakkoli, M.; Holmberg, N.; Kronberg, R.; Jiang, H.; Sainio, J.; Kauppinen, E. I.; Kallio, T.; Laasonen, K. Electrochemical Activation of Single-Walled Carbon Nanotubes with Pseudo-Atomic-Scale Platinum for the Hydrogen Evolution Reaction. ACS Catal. 2017, 7, 3121-3130.

(8) Dincă, M.; Surendranath, Y.; Nocera, D. G. Nickel-Borate Oxygen-Evolving Catalyst That Functions Under Benign Conditions. Proc. Natl. Acad. Sci. U.S.A. 2010, 107, 10337-10341.

(9) Gao, M.-R.; Xu, Y.-F.; Jiang, J.; Zheng, Y.-R.; Yu, S.-H. Water Oxidation Electrocatalyzed by an Efficient $\mathrm{Mn}_{3} \mathrm{O}_{4} / \mathrm{CoSe}_{2}$ Nanocomposite. J. Am. Chem. Soc. 2012, 134, 2930-2933.

(10) Gao, M.-R.; Xu, Y.-F.; Jiang, J.; Zheng, Y.-R.; Yu, S.-H. Correction to "Water Oxidation Electrocatalyzed by an Efficient $\mathrm{Mn}_{3} \mathrm{O}_{4} / \mathrm{CoSe}_{2}$ Nanocomposite". J. Am. Chem. Soc. 2013, 135, 6378.

(11) Trotochaud, L.; Ranney, J. K.; Williams, K. N.; Boettcher, S. W. Solution-Cast Metal Oxide Thin Film Electrocatalysts for Oxygen Evolution. J. Am. Chem. Soc. 2012, 134, 17253-17261.

(12) Zhang, B.; Zheng, X.; Voznyy, O.; Comin, R.; Bajdich, M.; García-Melchor, M.; Han, L.; Xu, J.; Liu, M.; Zheng, L.; et al. Homogeneously Dispersed Multimetal Oxygen-Evolving Catalysts. Science 2016, 352, 333-337.

(13) Ma, T. Y.; Dai, S.; Jaroniec, M.; Qiao, S. Z. Metal-Organic Framework Derived Hybrid $\mathrm{Co}_{3} \mathrm{O}_{4}$-Carbon Porous Nanowire Arrays as Reversible Oxygen Evolution Electrodes. J. Am. Chem. Soc. 2014, 136, 13925-13931.

(14) Kauffman, D. R.; Alfonso, D.; Tafen, D. N.; Lekse, J.; Wang, C.; Deng, X.; Lee, J.; Jang, H.; Lee, J.-s.; Kumar, S.; et al. Electrocatalytic Oxygen Evolution with an Atomically Precise Nickel Catalyst. ACS Catal. 2016, 6, 1225-1234.

(15) Chen, S.; Duan, J.; Ran, J.; Jaroniec, M.; Qiao, S. Z. N-Doped Graphene Film-Confined Nickel Nanoparticles as a Highly Efficient Three-Dimensional Oxygen Evolution Electrocatalyst. Energy Environ. Sci. 2013, 6, 3693-3699.

(16) Gong, M.; Li, Y.; Wang, H.; Liang, Y.; Wu, J. Z.; Zhou, J.; Wang, J.; Regier, T.; Wei, F.; Dai, H. An Advanced Ni-Fe Layered Double Hydroxide Electrocatalyst for Water Oxidation. J. Am. Chem. Soc. 2013, 135, 8452-8455.

(17) Tavakkoli, M.; Kallio, T.; Reynaud, O.; Nasibulin, A. G.; Sainio, J.; Jiang, H.; Kauppinen, E. I.; Laasonen, K. Maghemite Nanoparticles Decorated on Carbon Nanotubes as Efficient Electrocatalysts for the Oxygen Evolution Reaction. J. Mater. Chem. A 2016, 4, 5216-5222.

(18) Yang, J.; Fujigaya, T.; Nakashima, N. Decorating UnoxidizedCarbon Nanotubes with Homogeneous Ni-Co Spinel Nanocrystals Show Superior Performance for Oxygen Evolution/reduction Reactions. Sci. Rep. 2017, 7, No. 45384.

(19) Tavakkoli, M.; Nosek, M.; Sainio, J.; Davodi, F.; Kallio, T.; Joensuu, P. M.; Laasonen, K. Functionalized Carbon Nanotubes with $\mathrm{Ni}(\mathrm{II})$ Bipyridine Complexes as Efficient Catalysts for the Alkaline Oxygen Evolution Reaction. ACS Catal. 2017, 7, 8033-8041.

(20) Iijima, S. Helical Microtubules of Graphitic Carbon. Nature 1991, 354, 56-58.

(21) Novoselov, K. S.; Geim, A. K.; Morozov, S. V.; Jiang, D.; Zhang, Y.; Dubonos, S. V.; Grigorieva, I. V.; Firsov, A. A. Electric Field Effect in Atomically Thin Carbon Films. Science 2004, 306, 666-669.

(22) Dresselhaus, M. S.; Dresselhaus, G.; Saito, R. Physics of Nanotubes. Carbon 1995, 33, 883-891.

(23) Carbon Nanotubes: Synthesis, Structure, Properties, and Applications; Dresselhaus, M. S., Dresselhaus, G., Avouris, P., Eds.; Springer-Verlag: Berlin, 2001; Vol. 80.

(24) Jorio, A.; Saito, R.; Dresselhaus, G.; Dresselhaus, M. S. Raman Spectroscopy in Graphene Related Systems; Wiley-VCH Verlag: Weinheim, 2011; pp 17-51. 
(25) Gong, K.; Du, F.; Xia, Z.; Durstock, M.; Dai, L. NitrogenDoped Carbon Nanotube Arrays with High Electrocatalytic Activity for Oxygen Reduction. Science 2009, 323, 760-764.

(26) Hu, C.; Dai, L. Carbon-Based Metal-Free Catalysts for Electrocatalysis beyond the ORR. Angew. Chem., Int. Ed. 2016, 55, 11736-11758.

(27) Yadav, R. M.; Wu, J.; Kochandra, R.; Ma, L.; Tiwary, C. S.; Ge, L.; Ye, G.; Vajtai, R.; Lou, J.; Ajayan, P. M. Carbon Nitrogen Nanotubes as Efficient Bifunctional Electrocatalysts for Oxygen Reduction and Evolution Reactions. ACS Appl. Mater. Interfaces 2015, 7, 11991-12000.

(28) Lu, X.; Yim, W.-L.; Suryanto, B. H. R.; Zhao, C. Electrocatalytic Oxygen Evolution at Surface-Oxidized Multiwall Carbon Nanotubes. J. Am. Chem. Soc. 2015, 137, 2901-2907.

(29) Cheng, Y.; Tian, Y.; Fan, X.; Liu, J.; Yan, C. Boron Doped Multi-Walled Carbon Nanotubes as Catalysts for Oxygen Reduction Reaction and Oxygen Evolution Reaction in Alkaline Media. Electrochim. Acta 2014, 143, 291-296.

(30) Lin, Z.; Waller, G. H.; Liu, Y.; Liu, M.; Wong, C.-p. Simple Preparation of Nanoporous Few-Layer Nitrogen-Doped Graphene for Use as an Efficient Electrocatalyst for Oxygen Reduction and Oxygen Evolution Reactions. Carbon 2013, 53, 130-136.

(31) Li, R.; Wei, Z.; Gou, X. Nitrogen and Phosphorus Dual-Doped Graphene/Carbon Nanosheets as Bifunctional Electrocatalysts for Oxygen Reduction and Evolution. ACS Catal. 2015, 5, 4133-4142.

(32) Zhao, Y.; Nakamura, R.; Kamiya, K.; Nakanishi, S.; Hashimoto, K. Nitrogen-Doped Carbon Nanomaterials as Non-Metal Electrocatalysts for Water Oxidation. Nat. Commun. 2013, 4, No. 2390.

(33) Yang, H. B.; Miao, J.; Hung, S.-F.; Chen, J.; Tao, H. B.; Wang, X.; Zhang, L.; Chen, R.; Gao, J.; Chen, H. M.; et al. Identification of Catalytic Sites for Oxygen Reduction and Oxygen Evolution in NDoped Graphene Materials: Development of Highly Efficient MetalFree Bifunctional Electrocatalyst. Sci. Adv. 2016, 2, No. e1501122.

(34) El-Sawy, A. M.; Mosa, I. M.; Su, D.; Guild, C. J.; Khalid, S.; Joesten, R.; Rusling, J. F.; Suib, S. L. Controlling the Active Sites of Sulfur-Doped Carbon Nanotube-Graphene Nanolobes for Highly Efficient Oxygen Evolution and Reduction Catalysis. Adv. Energy Mater. 2016, 6, No. 1501966.

(35) Qu, K.; Zheng, Y.; Jiao, Y.; Zhang, X.; Dai, S.; Qiao, S. Polydopamine-Inspired, Dual Heteroatom-Doped Carbon Nanotubes for Highly Efficient Overall Water Splitting. Adv. Energy Mater. 2017, 7, No. 1602068.

(36) Davodi, F.; Tavakkoli, M.; Lahtinen, J.; Kallio, T. Straightforward Synthesis of Nitrogen-Doped Carbon Nanotubes as Highly Active Bifunctional Electrocatalysts for Full Water Splitting. J. Catal. 2017, 353, 19-27.

(37) Dai, L.; Xue, Y.; Qu, L.; Choi, H.-J.; Baek, J.-B. Metal-Free Catalysts for Oxygen Reduction Reaction. Chem. Rev. 2015, 115, 4823-4892.

(38) Friebel, D.; Louie, M. W.; Bajdich, M.; Sanwald, K. E.; Cai, Y.; Wise, A. M.; Cheng, M.-J.; Sokaras, D.; Weng, T.-C.; Alonso-Mori, R.; et al. Identification of Highly Active $\mathrm{Fe}$ Sites in $(\mathrm{Ni}, \mathrm{Fe}) \mathrm{OOH}$ for Electrocatalytic Water Splitting. J. Am. Chem. Soc. 2015, 137, 13051313.

(39) Ali-Löytty, H.; Louie, M. W.; Singh, M. R.; Li, L.; Sanchez Casalongue, H. G.; Ogasawara, H.; Crumlin, E. J.; Liu, Z.; Bell, A. T.; Nilsson, A.; et al. Ambient-Pressure XPS Study of a Ni-Fe Electrocatalyst for the Oxygen Evolution Reaction. J. Phys. Chem. C 2016, 120, 2247-2253.

(40) Dionigi, F.; Strasser, P. NiFe-Based (Oxy)hydroxide Catalysts for Oxygen Evolution Reaction in Non-Acidic Electrolytes. Adv. Energy Mater. 2016, 6, No. 1600621.

(41) Choi, Y. W.; Mistry, H.; Roldan Cuenya, B. New Insights into Working Nanostructured Electrocatalysts Through Operando Spectroscopy and Microscopy. Curr. Opin. Electrochem. 2017, 1, 95-103.

(42) Man, I. C.; Su, H.-Y.; Calle-Vallejo, F.; Hansen, H. A.; Martínez, J. I.; Inoglu, N. G.; Kitchin, J.; Jaramillo, T. F.; Nørskov, J. K.; Rossmeisl, J. Universality in Oxygen Evolution Electrocatalysis on Oxide Surfaces. ChemCatChem 2011, 3, 1159-1165.
(43) Rossmeisl, J.; Logadottir, A.; Nørskov, J. K. Electrolysis of Water on (oxidized) Metal Surfaces. Chem. Phys. 2005, 319, 178184.

(44) Rossmeisl, J.; Qu, Z. W.; Zhu, H.; Kroes, G. J.; Nørskov, J. K. Electrolysis of Water on Oxide Surfaces. J. Electroanal. Chem. 2007, 607, 83-89.

(45) Rossmeisl, J.; Dimitrievski, K.; Siegbahn, P.; Nørskov, J. K. Comparing Electrochemical and Biological Water Splitting. J. Phys. Chem. C 2007, 111, 18821-18823.

(46) Srivastava, D.; Susi, T.; Borghei, M.; Laasonen, K. Dissociation of Oxygen on Pristine and Nitrogen-Doped Carbon Nanotubes: A Spin-Polarized Density Functional Study. RSC Adv. 2014, 4, 1522515235 .

(47) Ni, S.; Li, Z.; Yang, J. Oxygen Molecule Dissociation on Carbon Nanostructures with Different Types of Nitrogen Doping. Nanoscale 2012, 4, 1184-1189.

(48) Shan, B.; Cho, K. Oxygen Dissociation on Nitrogen-Doped Single Wall Nanotube: A First-Principles Study. Chem. Phys. Lett. 2010, 492, 131-136.

(49) Choi, C. H.; Lim, H.-K.; Chung, M. W.; Park, J. C.; Shin, H.; Kim, H.; Woo, S. I. Long-Range Electron Transfer over GrapheneBased Catalyst for High-Performing Oxygen Reduction Reactions: Importance of Size, N-Doping, and Metallic Impurities. J. Am. Chem. Soc. 2014, 136, 9070-9077.

(50) Holmberg, N.; Laasonen, K. Theoretical Insight into the Hydrogen Evolution Activity of Open-Ended Carbon Nanotubes. J. Phys. Chem. Lett. 2015, 6, 3956-3960.

(51) Holmberg, N.; Laasonen, K. Ab Initio Electrochemistry: Exploring the Hydrogen Evolution Reaction on Carbon Nanotubes. J. Phys. Chem. C 2015, 119, 16166-16178.

(52) Tuomi, S.; Pakkanen, O. J.; Borghei, M.; Kronberg, R.; Sainio, J.; Kauppinen, E. I.; Nasibulin, A. G.; Laasonen, K.; Kallio, T. Experimental and Computational Investigation of Hydrogen Evolution Reaction Mechanism on Nitrogen Functionalized Carbon Nanotubes. Chem CatChem 2018, 10, 3872-3882.

(53) Li, M.; Zhang, L.; Xu, Q.; Niu, J.; Xia, Z. N-Doped Graphene as Catalysts for Oxygen Reduction and Oxygen Evolution Reactions: Theoretical Considerations. J. Catal. 2014, 314, 66-72.

(54) Hessels, J.; Detz, R. J.; Koper, M. T. M.; Reek, J. N. H. Rational Design Rules for Molecular Water Oxidation Catalysts Based on Scaling Relationships. Chem. - Eur. J. 2017, 23, 16413-16418.

(55) Najafpour, M. M.; Renger, G.; Holyńska, M.; Moghaddam, A. N.; Aro, E.-M.; Carpentier, R.; Nishihara, H.; Eaton-Rye, J. J.; Shen, J.-R.; Allakhverdiev, S. I. Manganese Compounds as Water-Oxidizing Catalysts: From the Natural Water-Oxidizing Complex to Nanosized Manganese Oxide Structures. Chem. Rev. 2016, 116, 2886-2936.

(56) Perdew, J. P.; Burke, K.; Ernzerhof, M. Generalized Gradient Approximation Made Simple. Phys. Rev. Lett. 1996, 77, 3865-3868.

(57) Grimme, S.; Antony, J.; Ehrlich, S.; Krieg, H. A Consistent and Accurate $A b$ Initio Parametrization of Density Functional Dispersion Correction (DFT-D) for the 94 Elements H-Pu. J. Chem. Phys. 2010, 132, No. 154104

(58) Grimme, S.; Ehrlich, S.; Goerigk, L. Effect of the Damping Function in Dispersion Corrected Density Functional Theory. J. Comput. Chem. 2011, 32, 1456-1465.

(59) VandeVondele, J.; Krack, M.; Mohamed, F.; Parrinello, M.; Chassaing, T.; Hutter, J. Quickstep: Fast and Accurate Density Functional Calculations Using a Mixed Gaussian and Plane Waves Approach. Comp. Phys. Commun. 2005, 167, 103-128.

(60) Hutter, J.; Iannuzzi, M.; Schiffmann, F.; VandeVondele, J. CP2K: Atomistic Simulations of Condensed Matter Systems. Wiley Interdiscip. Rev.: Comput. Mol. Sci. 2014, 4, 15-25.

(61) CP2K Developers Group, version 4.1, 2016. https://www.cp2k. org/.

(62) VandeVondele, J.; Hutter, J. Gaussian Basis Sets for Accurate Calculations on Molecular Systems in Gas and Condensed Phases. J. Chem. Phys. 2007, 127, No. 114105. 
(63) Goedecker, S.; Teter, M.; Hutter, J. Separable Dual-Space Gaussian Pseudopotentials. Phys. Rev. B: Condens. Matter Mater. Phys. 1996, 54, 1703-1710.

(64) Hartwigsen, C.; Goedecker, S.; Hutter, J. Relativistic Separable Dual-Space Gaussian Pseudopotentials from H to Rn. Phys. Rev. B 1998, 58, 3641-3662.

(65) Krack, M. Pseudopotentials for $\mathrm{H}$ to $\mathrm{Kr}$ Optimized for Gradient-Corrected Exchange-Correlation Functionals. Theor. Chem. Acc. 2005, 114, 145-152.

(66) Ayala, P.; Arenal, R.; Rümmeli, M.; Rubio, A.; Pichler, T. The Doping of Nanotubes with Nitrogen and Their Potential Applications. Carbon 2010, 48, 575-586.

(67) Arenal, R.; March, K.; Ewels, C. P.; Rocquefelte, X.; Kociak, M.; Loiseau, A.; Stéphan, O. Atomic Configuration of Nitrogen-Doped Single-Walled Carbon Nanotubes. Nano Lett. 2014, 14, 5509-5516.

(68) Susi, T.; Pichler, T.; Ayala, P. X-Ray Photoelectron Spectroscopy of Graphitic Carbon Nanomaterials Doped with Heteroatoms. Beilstein J. Nanotechnol. 2015, 6, 177-192.

(69) Kaukonen, M.; Kujala, R.; Kauppinen, E. I. On the Origin of Oxygen Reduction Reaction at Nitrogen-Doped Carbon Nanotubes: A Computational Study. J. Phys. Chem. C 2012, 116, 632-636.

(70) Haddon, R. C. Chemistry of the Fullerenes: The Manifestation of Strain in a Class of Continuous Aromatic Molecules. Science 1993, 261, 1545-1550.

(71) Dumitrică, T.; Landis, C. M.; Yakobson, B. I. CurvatureInduced Polarization in Carbon Nanoshells. Chem. Phys. Lett. 2002, $360,182-188$.

(72) Gülseren, O.; Yildirim, T.; Ciraci, S. Tunable Adsorption on Carbon Nanotubes. Phys. Rev. Lett. 2001, 87, No. 116802.

(73) Frydendal, R.; Busch, M.; Halck, N. B.; Paoli, E. A.; Krtil, P.; Chorkendorff, I.; Rossmeisl, J. Enhancing Activity for the Oxygen Evolution Reaction: The Beneficial Interaction of Gold with Manganese and Cobalt Oxides. ChemCatChem 2015, 7, 149-154.

(74) Gorlin, Y.; Chung, C.-J.; Benck, J. D.; Nordlund, D.; Seitz, L.; Weng, T.-C.; Sokaras, D.; Clemens, B. M.; Jaramillo, T. F. Understanding Interactions Between Manganese Oxide and Gold That Lead to Enhanced Activity for Electrocatalytic Water Oxidation. J. Am. Chem. Soc. 2014, 136, 4920-4926.

(75) Busch, M.; Halck, N. B.; Kramm, U. I.; Siahrostami, S.; Krtil, P.; Rossmeisl, J. Beyond the Top of the Volcano? A Unified Approach to Electrocatalytic Oxygen Reduction and Oxygen Evolution. Nano Energy 2016, 29, 126-135.

(76) Chakthranont, P.; Kibsgaard, J.; Gallo, A.; Park, J.; Mitani, M.; Sokaras, D.; Kroll, T.; Sinclair, R.; Mogensen, M. B.; Jaramillo, T. F. Effects of Gold Substrates on the Intrinsic and Extrinsic Activity of High-Loading Nickel-Based Oxyhydroxide Oxygen Evolution Catalysts. ACS Catal. 2017, 7, 5399-5409.

(77) Partanen, L.; Murdachaew, G.; Laasonen, K. Oxygen Evolution Reaction Kinetic Barriers on Nitrogen-Doped Carbon Nanotubes. J. Phys. Chem. C 2018, 122, 12892-12899. 